\title{
3D INDOOR ROUTING FOR FIRE EVACUATION PLANNING INSIDE MAIN LIBRARY, UP DILIMAN
}

\author{
Marion Clarisse L. Gelido, Catherine Rose A. Tatlonghari, Edgardo G. Macatulad, Alexis Richard C. Claridades* \\ Department of Geodetic Engineering, College of Engineering, University of the Philippines - Diliman \\ acclaridades@up.edu.ph
}

KEY WORDS: 3D Indoor GIS, Indoor Routing, Fire Evacuation, Network Analysis

\begin{abstract}
:
3D indoor GIS is now being widely used as its improved spatial visualization can be applied to a variety of projects - one of which is emergency management in multi-level buildings. This study assesses the fire evacuation plan of the Main Library in the University of the Philippines - Diliman using 3D indoor GIS. Currently, the Main Library has a two-dimensional fire evacuation plan for every floor all following general routes to several exit points. With 3D indoor routing using GIS and network analysis, an origin-based and scenario-dependent evacuation management plan is created to have a more systematic process for fire events. Certain factors priority of resources, origin of fire, all possible routes and exits, duration of evacuation - were used as basis of the fire evacuation plan assessment. The resulting geometric 3D model of Main Library is presented with both the library patron routes and staff routes that have stops along the way in to save priority resources before proceeding to exit points. Color-coded routes are mapped out symbolizing evacuation time while the route line thickness represents the population count in each route. Furthermore, three obstruction scenarios were created in order to simulate a fire event. Although a fire model was not considered, the scenarios proved to show the versatility of the generated routes in accordance to each case. Additionally, two new exit points were suggested for the ease of the library staff - who had a much longer evacuation time - resulting to an average time deficit of 15.25 seconds.
\end{abstract}

\section{INTRODUCTION}

\subsection{Background}

While GIS is mostly used on open spaces, the rise of threedimensional (3D) indoor GIS allows for the technology to be applied in an indoor setting such as emergency management planning (Cao and $\mathrm{Lu}, 2012$ ). The complex layout of indoor spaces can be realistically represented - especially for multileveled, complex buildings - with entities such as walls, passages, and physical obstructions, thus creating more accurate and detailed evacuation strategies to improve upon the current two-dimensional (2D) evacuation plans (Tsiliakou et al., 2016).

Network analysis is a tool that GIS specialists use in order to solve transportation problems. This can be used for indoor navigation, with the $3 \mathrm{D}$ aspect adding dimension and spatiality (Musliman et al., 2008).

Constructed in January 1951, the Gonzalez Hall in UP Diliman is one of the oldest buildings in the campus ("University Library | University Library, University of the Philippines Diliman," n.d.). The Gonzalez Hall which houses the Main Library within three floors is where a great number of valuable and irreplaceable books and references collected throughout time. The numerous paper materials kept in the building and the large volume of people coming and going expose the building to greater endangerments should a fire incident occur ("Main Library | University Library, University of the Philippines Diliman," n.d.). Preventing this type of disaster is important in ensuring the safety of not only the people inside, but also of the peerless contents stored in the building. A fire evacuation plan that considers all these factors must be applied in order to minimize the disaster in cases of fire incidents.

This evacuation plan should be capable of successfully evacuating not only the people but also the resources - books, archives, and other information material - out of the building when a fire hazard arises. To ensure the efficiency of the fire management plans, the best possible routes during path deviations for obstruction encounters and which resources should be prioritized are considered. If the current evacuation plan is deemed substandard, improvements will be made on it. Additionally, introducing a three-dimensional aspect allows for better visualization and more parameters such as time and distance to consider when making an evacuation management plan.

Current evacuation plans in the Main Library were constructed on a floor-by-floor basis, in two-dimensions. They are crafted subjectively, based on the visual interpretation on which exits are closest to each room. With 3D GIS and network analysis, the fire evacuation plan can be further improved for the benefit of the Main Library and the UPD community by generating plans based on actual distances on the building pathways, and quantitatively evaluating these based on the currentlyimplemented plans.

\subsection{Objectives and Expected Output}

This study aims to perform 3D network analysis in a generated geometric 3D indoor GIS model of the Main Library in the University of the Philipines - Diliman to assess the current fire evacuation plan of the building. Three obstruction scenarios will also be considered from which new evacuation routes will be generated tailored for each scenario. These new routes will be evaluated and compared with the current evacuation plan of the building and new street level exit points will also be determined to ease the flow of evacuation.

\subsection{Scope and Limitations}

This study is focused on the Main Library of the University of the Philippines - Diliman which consists of the first three floors of Gonzalez Hall - basement, ground floor, and second floor. The fire management plan is only confined within the Main Library where evacuation routes end at the street level fire exit points of the building. 
Human behavior - including real time delays due to human factors and personal health situations during fire incidents will not be considered, as the routes will be assessed based only on the shortest distance and time with a generalized brisk walking speed it takes to get to an exit point. A fire model will not be incorporated in the study as the fire scenarios created will be static and confined only to certain locations. The behavior of fire will not be modeled as this study mainly focuses on evacuation routes.

Building structure - such as the age and type of materials used in constructing the building - will not be considered when analyzing the behavior of fire as this study will purely focus on the layout and floor plan of Gonzalez Hall. The 3D models generated will be simplistic as building designs are not implemented to the models however, building factors such as dimensions of room area, exit capacity and corridor length are thoroughly measured as they present an important aspect in creating the fire evacuation routes.

A constant brisk walking evacuation speed of $1.788 \mathrm{~m} / \mathrm{s}$ was used in the study. Library staff members assigned to save the priority resources of the building were given 15 seconds for each stop to collect said resources. The population count used for library patrons was 519, as based on the maximum occupancy of the Main Library.

\section{REVIEW OF RELATED LITERATURE}

\subsection{D GIS and Emergency Management}

Emergency management is the evacuation of people from danger zones to safety exit points in the shortest amount of time possible (Chen \& Feng, 2009). The construction of multi-level buildings created complex indoor environments making indoor navigation challenging, especially during emergencies, due to the limited access to street level exit points (Cao and $\mathrm{Lu}, 2012$; Kwan and Lee, 2005). The development of 3D technologies allow for better and more realistic representations of the real world, including the ability to perform spatial analysis on these 3D models (Makdoom, 2015).

The capability of GIS to analyze spatial features in small regions such as indoor spaces allow it to be utilized in emergency management, providing better details for accuracy and efficiency (Tang and Ren, 2011). 3D network-based datasets also enable support for routing and navigation solutions with turn-by-turn directions make it suitable for evacuation management (Makdoom, 2015).

\subsection{D Network Analysis}

3D network analysis can be used to find the shortest path within indoor spaces for emergency management in complex, multilevel buildings (Cao and Lu, 2012). A network-based model makes use of nodes and edges - where nodes represent building units and edges represent the distance between the two units or nodes. Rooms are then represented by nodes, while the flow of people are represented by the edges. The people travel between nodes until they reach and exit node for evacuation.

The minimum calculations required and fast computing speed of this model makes it advantageous to use, but it does make for a very simple representation of movement (Xiong et al., 2017). The 3D network-based data model can be used in assessing the effect in response time of uncertainties encountered during emergency evacuations which include entry point uncertainty and route uncertainty in an indoor space (Kwan and Lee, 2005).

\section{METHODOLOGY}

The general methodology of the study can be seen in figure 2 below. Firstly, the data collected for this study are the Gonzalez Hall building blueprint, location of valuable resources that must be prioritized for evacuation, patron and staff population statistics within the Main Library, and the current evacuation plans. With the building blueprints, the 3D geometric model of the building was created in SketchUp.

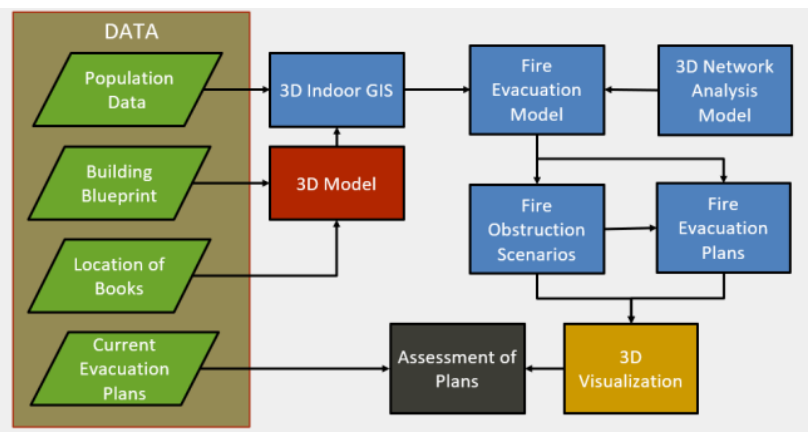

Figure 1. General methodology

A network dataset was then constructed using nodes and edges in ArcMap, where the occupied spaces of both patrons and staff and the location of priority resources were taken into consideration. Adding a $\mathrm{Z}$ value to the nodes and edges allowed the network to be translated into a 3D model. With the network set up, network analysis was performed to determine the best evacuation routes that led to the nearest exit point possible. The maximum occupancy of the Main Library was also considered for the population count data.

To further create a realistic fire event, fire obstruction scenarios were added where new evacuation routes tailored to the situation were generated. These routes were exported from the network analysis layers and then imported into ArcScene for the $3 \mathrm{D}$ visualization. The $3 \mathrm{D}$ model created was also imported into ArcScene, completing the generated 3D fire evacuation plan of the Main Library. Since both length and time were used as accumulators in the network analysis, the routes generated included these total distance and time it takes for each route to reach an exit point. Finally, the 3D fire evacuation model will be assessed according to time duration of the evacuation route and the current $2 \mathrm{D}$ fire evacuation plan provided.

\section{3D MODELING}

\subsection{D Modeling of Main Library, UP DIliman}

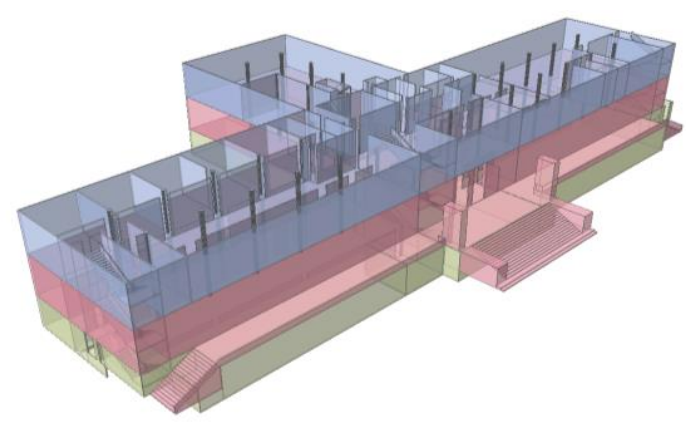

Figure 2. 3D Model of Main Library in UP Diliman 
The 3D model of the building and its floor plan was generated using SketchUp 2018 using the blueprint data obtained from the University Library Emergency Management Committee and the Office of the Campus Architect. The model was created in a simplistic form - without the architectural details - as only the rooms and the corridors were essential in creating the fire evacuation plans.

\subsection{D Network Analysis}

Indoor 3D routing was achieved using the Network Analyst tool in ArcMap 10.3. The network was created using nodes and edges which were represented by point and line feature classes respectively. $\mathrm{Z}$ values were added to these feature classes to allow the network to be visualized in 3D. The parameters considered in the network analysis were length (meters) and time (seconds).

Two sets of networks were created for each floor in the Main Library - one for the library patrons and another for the library staff. Separate networks were created since the staff and the patrons occupy distinct areas in the building, some of which are for the exclusive use only of the staff. Special library staff members are assigned to save the priority resources of the Main Library in case of fire accidents. These staff members each have their own tailored routes where they will be heading to the locations of important resources first to salvage as much as they can before going to an exit point.

In calculating evacuation times, a speed of $1.788 \mathrm{~m} / \mathrm{s}$ was assumed for each person, based on the number of steps a person with a height below 5'6" takes, as verified by a pedometer that can measure walking speed. Special library staff will be given a maximum of 15 seconds for each stop they have to make. This 15 -second allowance is assumed to be sufficient for these staff members to save resources within a 3.5-meter radius.

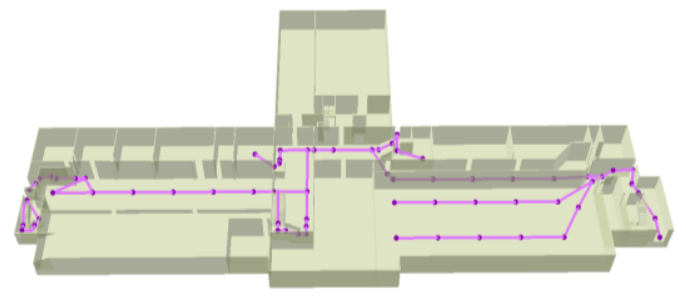

Figure 3. Library Patron Basement Network

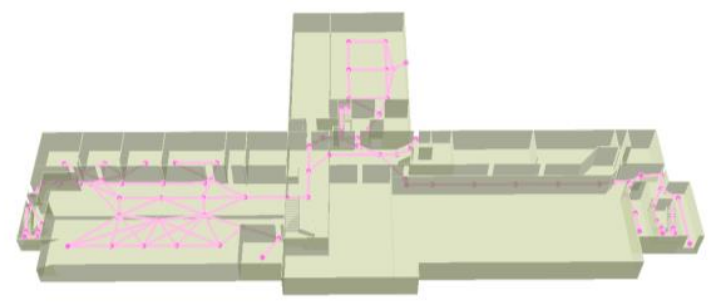

Figure 4. Library Staff Basement Network

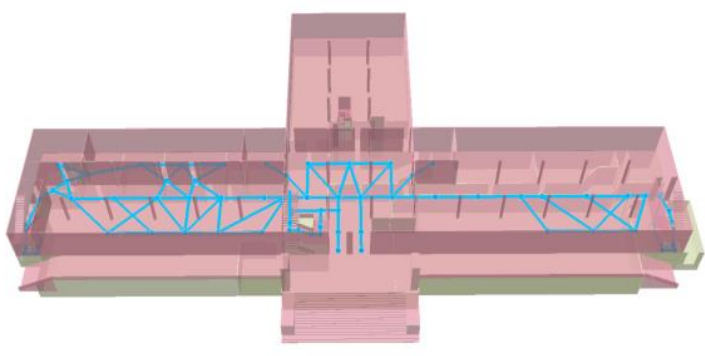

Figure 5. Library Patron Ground Floor Network

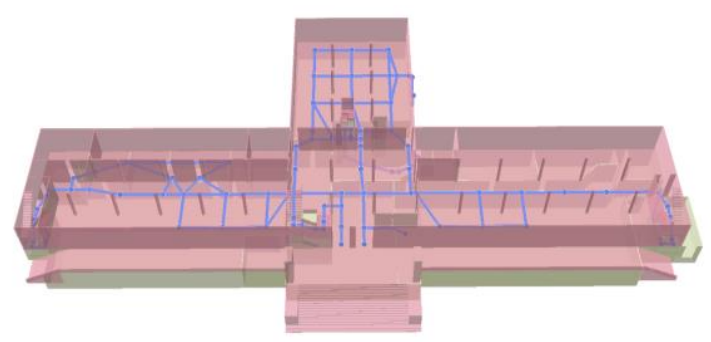

Figure 6. Library Staff Ground Floor Network

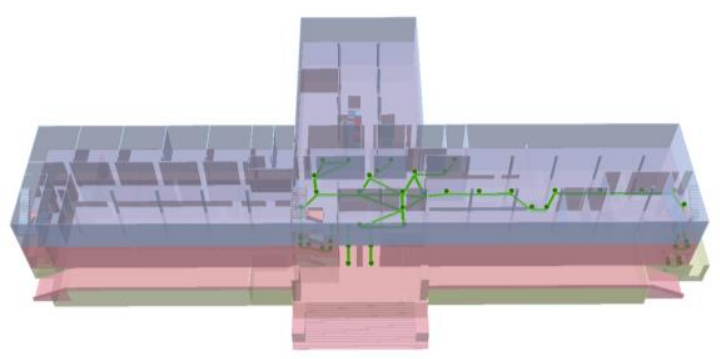

Figure 7. Library Patron Second Floor Network

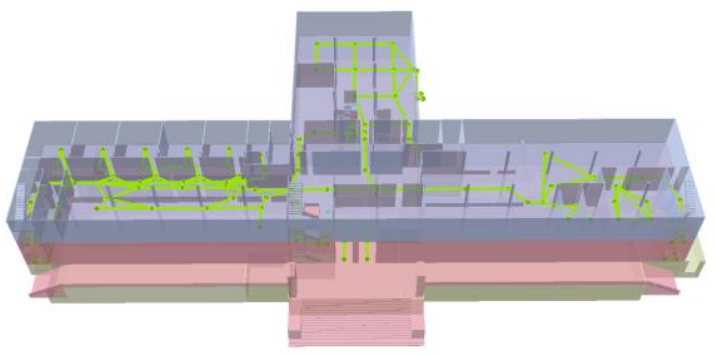

Figure 8. Library Staff Second Floor Network

\section{FIRE EVACUATION MODELING}

\subsection{Generated Evacuation Routes}

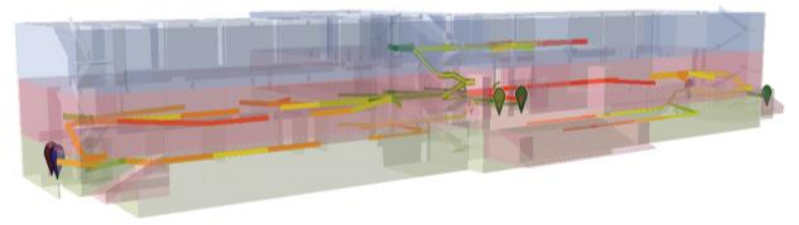

Figure 9. Generated patron evacuation routes

Figure 9 above shows the generated evacuation routes for library patrons in the Main Library. The closest facility analysis layer was employed to produce the shortest routes to get to a street level exit point. 


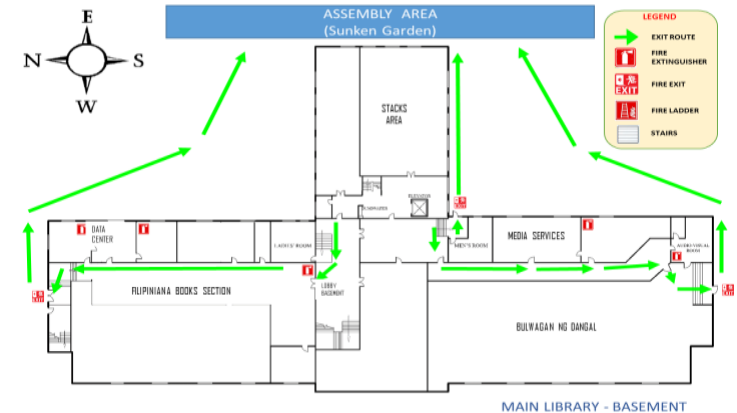

Figure 10. Currently Implemented Evacuation Basement Routes

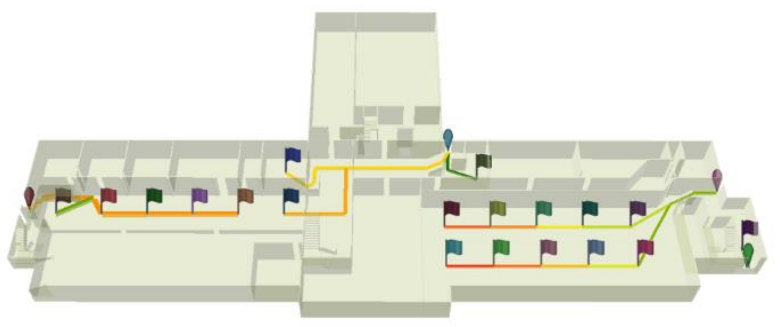

Figure 11. Generated Evacuation Basement Routes

Figure 4.1 below shows the generated evacuation routes for patrons in the basement and the current evacuation routes stated in the emergency management plan of the Main Library. A population count of 80 was considered in the patron basement evacuation process. There are small variations between the two, as the generated routes utilized the east basement exit more than the current evacuation plan. All the patrons in the north wing were designated to use the north basement exit 2 , but the generated routes show that patrons closer to the east basement exit should instead use it as their exit point.

Based on the resulting data, those coming from Bulwagan 1 the innermost corner of the Bulwagan ng Dangal - will have the longest route to traverse to reach an exit point during evacuation, taking 27.63 seconds to reach the south basement exit. Patrons in the basement have an average evacuation time of 15.46 seconds with a distance of 27.63 meters to reach an exit point.

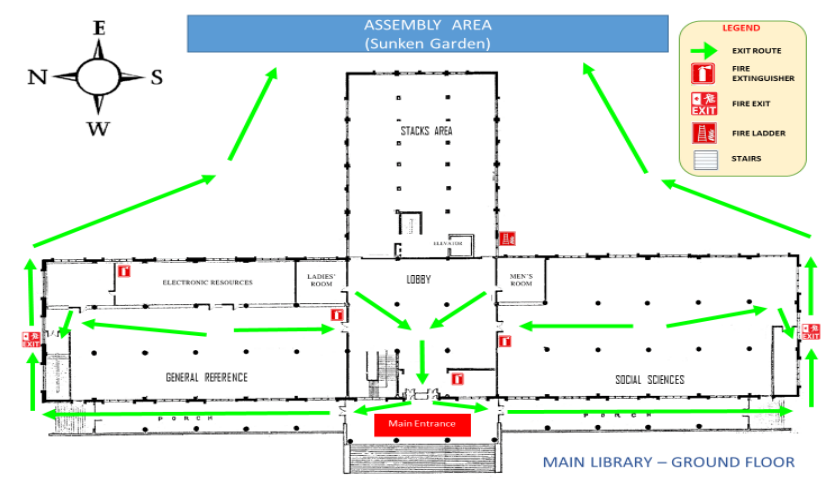

Figure 12. Currently Implemented Evacuation Ground Floor Routes

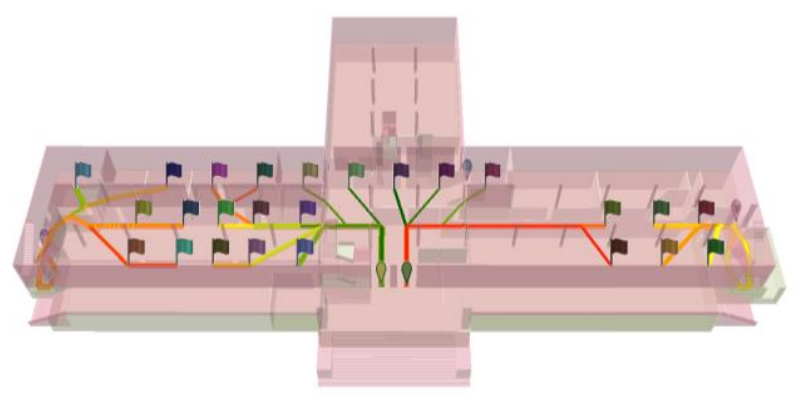

Figure 13. Generated Evacuation Ground Floor Routes

For the ground floor, the average evacuation time of patrons in this level is 18.46 seconds. Occupants in the lobby have the shortest evacuation time of 10.13 seconds while those in the middle of the south wing in the Social Sciences section have the longest evacuation time totaling to 25.35 seconds. Patrons in the ground floor have to traverse an average distance of 33.01 meters to get to an exit point. Evacuation routes in this level have an average evacuation time of 18.46 seconds.

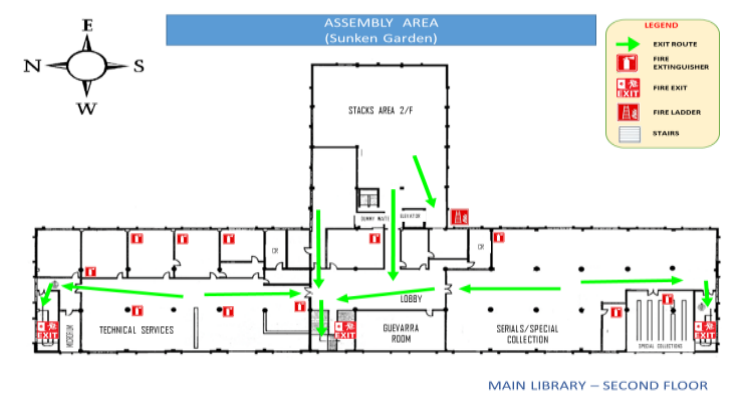

Figure 14. Currently Implemented Evacuation 2nd Floor Routes

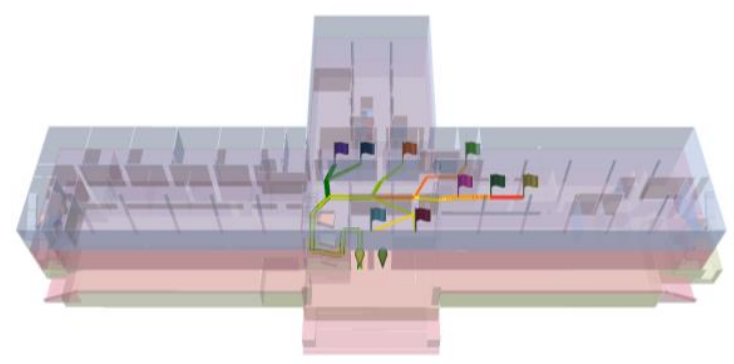

Figure 15. Generated Evacuation 2nd Floor Routes

For the second floor, the longest route will be for those occupants in the serials section with an evacuation time of 36.11 seconds. The shortest route will be for those in the conference room, with an evacuation time of 22.29 seconds. The average evacuation time in the second floor for patrons is 29.49 seconds with an average travel distance of 52.72 meters. The distance and time obtained in this level is higher compared to those in the lower levels since there is no direct access in the floor to street level exits. For patrons in the second floor, only the ground floor exit was utilized in the evacuation process as this was the nearest street level exit point. 


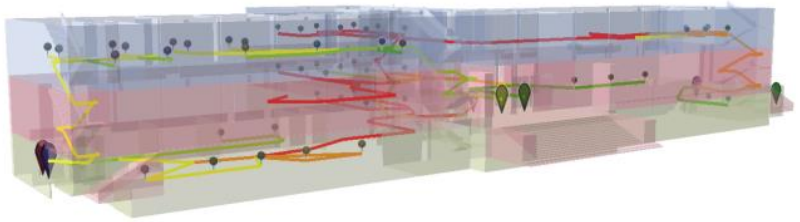

Figure 16. Generated library staff evacuation routes

To rescue the valuable resources in the library, a 15-second time attribute was given to stops where they must collect resources. Each route was tailored specifically for a single staff member, from their origin to the locations of priority resources and finally to an exit point. A single staff member was given a maximum of three stops for the collection of priority resources.

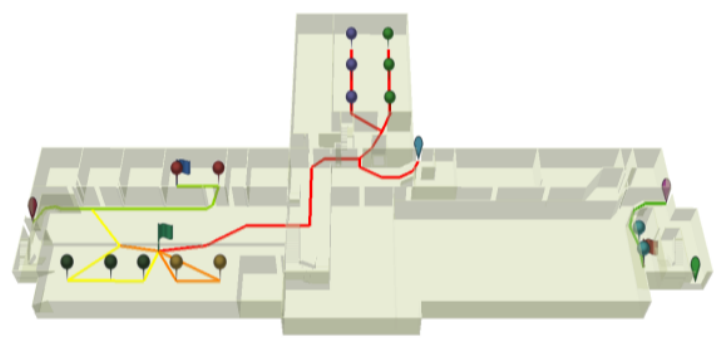

Figure 17. Generated Staff Evacuation Basement Routes

With an additional 15 seconds for each stop they have to make, special staff members take longer to reach an exit point. As seen above, the longest evacuation route takes 109.39 seconds to complete for the staff stationed in the Filipiniana section assigned to save resources in the storage room. The shortest route taked 38.59 seconds, for the staff stationed in the microfilm storage room designated to save the resources in that very room.

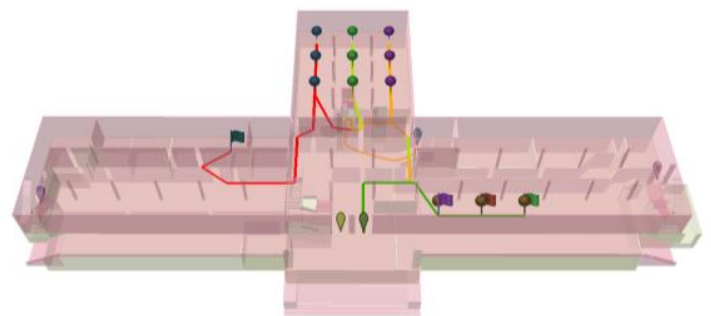

Figure 18. Generated Staff Evacuation Ground Floor Routes

The shortest evacuation time is for the staff member saving resources in the Social Science section, which only amounts to 68.43 seconds. The average time of evacuation of special staff in this floor is 96.34 seconds.

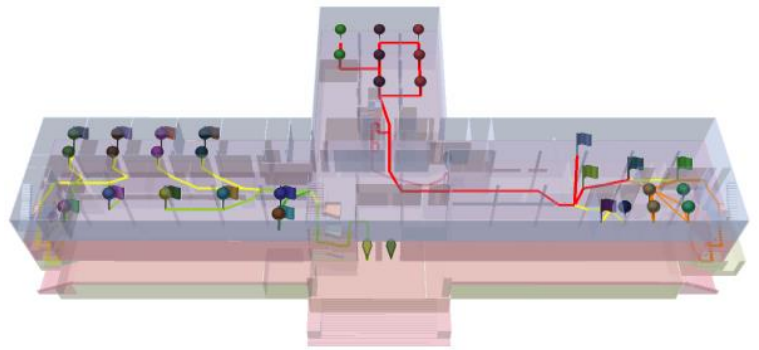

Figure 19. Generated Staff Evacuation Second Floor Routes

Rooms that contain priority resources in the second floor include the rare books room, the special collections room, the second floor storage room, the administration offices, the technical services division, the microfilm room and laboratory, and the Office of the University Librarian. The longest routes are for staff assigned to save resources in the storage room, with a travel time of 130.59 seconds. The average evacuation time for staff members in this level is 66.26 seconds.

\subsection{Obstruction Scenarios}

Three hypothetical obstruction scenarios were created in the study based on the likelihood of fire starting in the building. These indoor spaces include the data center rooms in the north wing of the basement, the data server room in the north wing of the second floor, and the laptop charging table in the north wing of the ground floor. New evacuation routes were then generated from each scenario.

\subsubsection{Obstruction Scenario 1: Fire in the Data Center Room}

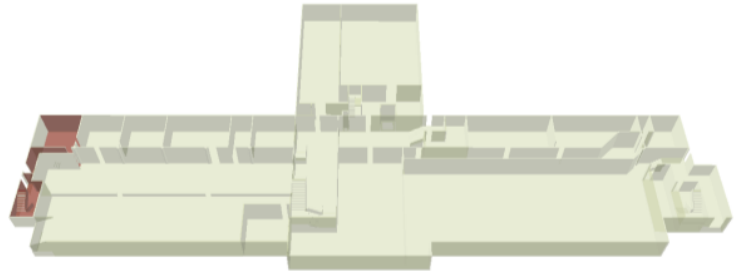

Figure 20. Obstruction Scenario in the Data Center Room

The first obstruction scenario involved a fire in the data center room in the basement as large data server machines could be a cause of fire. Moreover, as the data center is next to the north basement exit 1 , this exit point was blocked. The north basement exit that is accessible only to those from upper floors was also blocked. The area displayed in red in Fig. 21 shows the origin of fire and the affected exit point. Routes that lead to these exit points were recalculated to locate the next closest exit point.

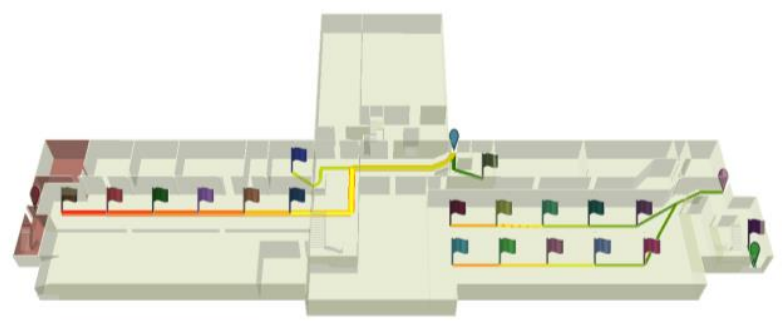

Figure 21. Generated Evacuation Basement Floor Routes for First Evacuation Scenario

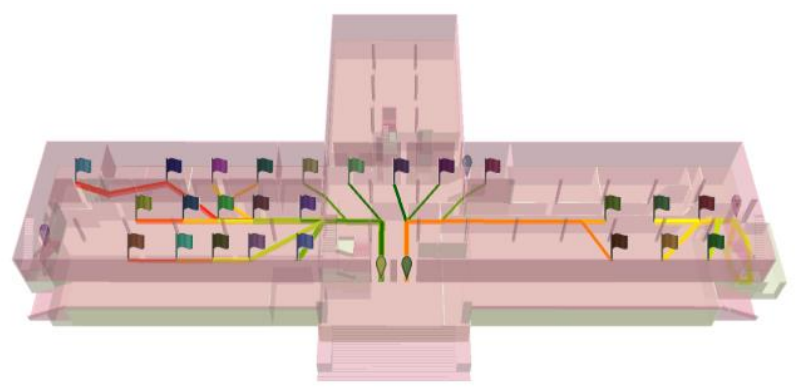

Figure 22. Generated Evacuation Ground Floor Routes for First Evacuation Scenario 


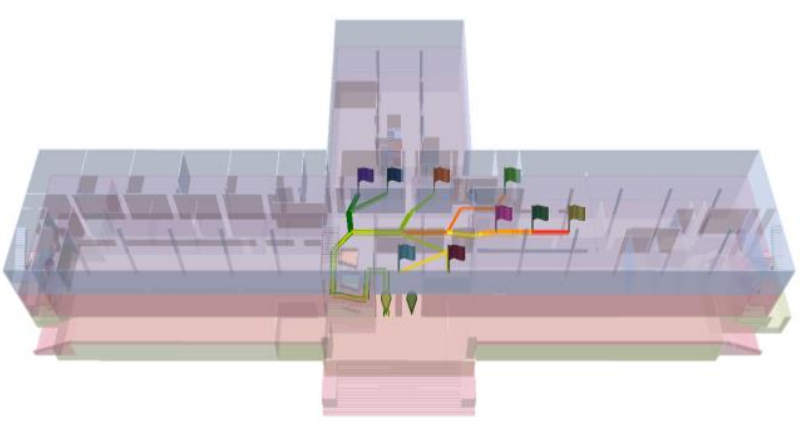

Figure 23. Generated Evacuation Second Floor Routes for First Evacuation Scenario

The new evacuation routes generated for all floors from the blockage in the north basement exit points can be seen in Figure 21 to 23 to the unavailability of the north basement exit points, those in the north wing of the basement had to use to the east exit basement instead. North wing ground floor occupants were led to the ground floor exits in the main lobby. Meanwhile, those in the second floor had to use the main staircase in the lobby to reach the ground floor lobby exit points.

For the patron evacuation routes that were mainly affected were those from the basement and ground floors as most routes avoided the north basement exit points, however the evacuation routes for he patrons on the second floor showed no change since the north wing of the second floor is not accessible to them. The change in evacuation routes caused a longer evacuation duration of 4.93 seconds and 1.63 seconds respectively for the basement and ground floor.

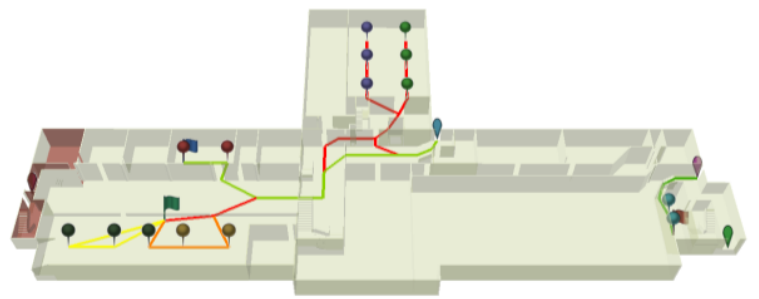

Figure 24. Generated Evacuation Basement Routes of Library Staff for First Evacuation Scenario

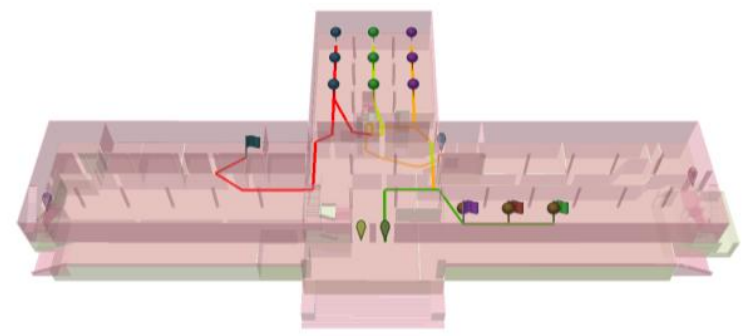

Figure 25. Generated Evacuation Ground Floor Routes of Library Staff for First Evacuation Scenario

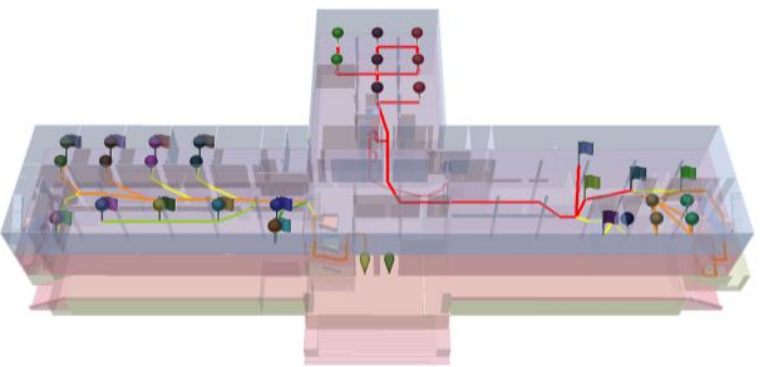

Figure 26. Generated Evacuation Second Floor Routes of Library Staff for First Evacuation Scenario

Staff members in the basement had to use the east basement exit to reach safety. Those in the north wing of the both ground and second floors were now designated to use the ground floor lobby exit points, passing through the main staircase of the building. This obstruction scenario not only caused congestion in the east basement exit and in the ground floor lobby exits, but also lengthen the evacuation time to 17.94 seconds for the basement and 2.64 seconds for the second floor. As the east basement exit is mostly allotted for the use of staff with save stops, this triggered problems in the process of saving the prioritized resources of the Main Library and the safety of the library staff doing so.

\subsubsection{Obstruction Scenario 1: Obstruction in the Data Server Room}

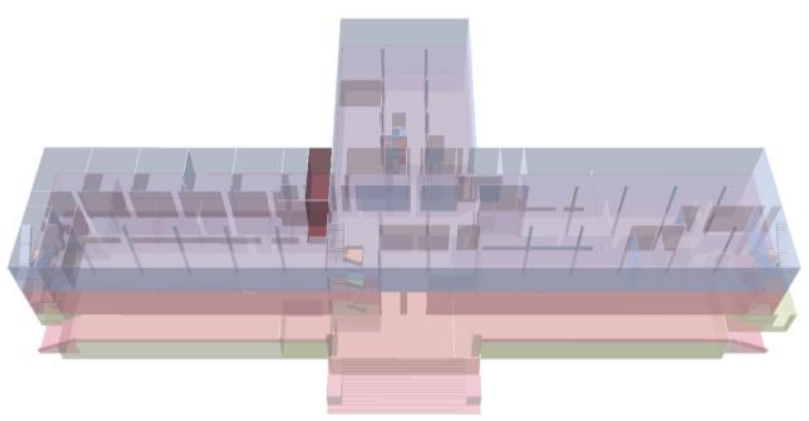

Figure 27. Obstruction Scenario in the Data Server Room

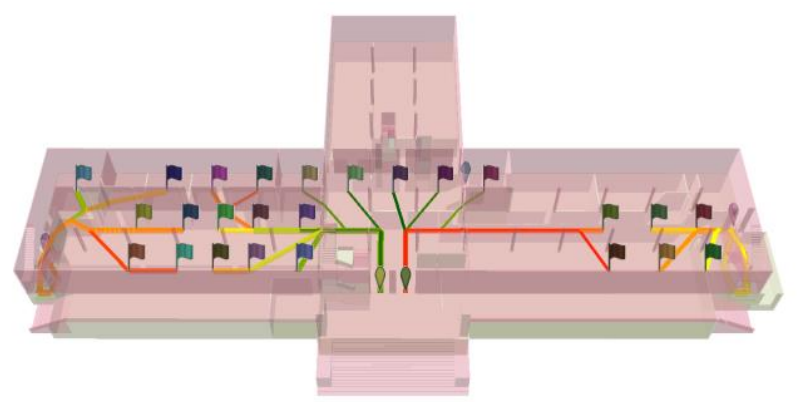

Figure 28. Generated Evacuation Second Floor Routes of Library Patrons for Second Evacuation Scenario

The second obstruction scenario in the data server room mainly affected occupants of the second floor, while the evacuation routes for the lower floors remained the same. In the new routes due to the second fire instead of using the main staircase to reach the ground floor exit points, the south and north staircases were instead utilized to reach the south and north basement exit points, respectively. Additionally, the change in routes for the patrons from the second floor created some congestion for both 
the south and north basement exit points. This scenario resulted to an increase of 23.72 seconds in evacuation duration.

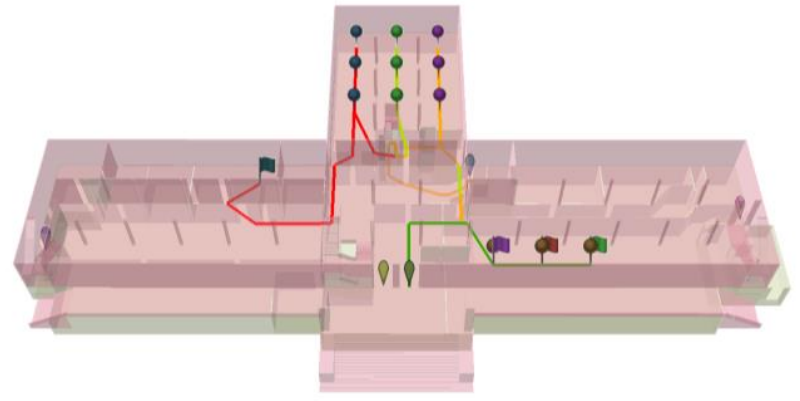

Figure 29. Generated Evacuation Second Floor Routes of Library Staff for Second Evacuation Scenario

Identical with the patron evacuation routes, the only evacuation routes affected by the second fire obstruction scenario were the library staff situated in the second floor. Evacuation routes of staff in the basement and ground floor remained unchanged, as observed in figure 4.12. For this case, the main staircase in the second floor lobby is left avoided as it was near the origin of the fire and the north and south wing basement exits were mainly used by the staff to evacuate. Not only did this pose congestion problems in the north and south wing basement exits, but also had a longer time of evacuation for 5.46 seconds.

\subsubsection{Obstruction Scenario 1: Obstruction in the General Reference Section}

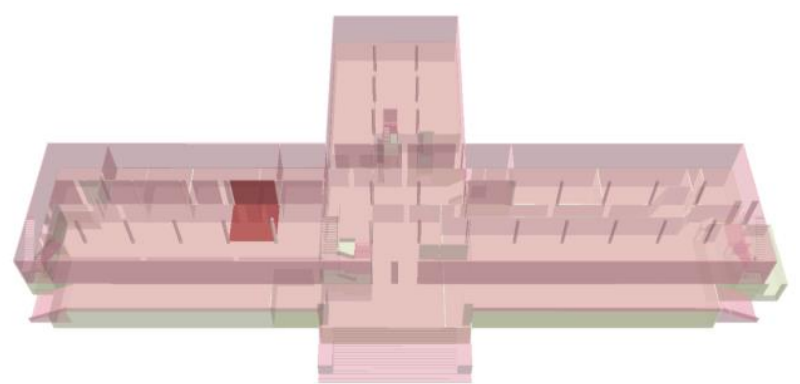

Figure 30. Obstruction Scenario in the General Reference Section

The third obstruction scenario demonstrated a fire breaking out in the General Reference section in the north wing of the ground floor of the Main Library. The area in colored in red in Fig. 30 is where patrons are free to charge their electronic devices. This area may cause a fire due to misuse of extension cords and whether chargers are directly plugged in or not as these are the tables designated for people who are in need of laptop charging or other electricity use. The General Reference section being the most populated area of the library at all times, was also the only location in the building can be occupied by people until midnight.

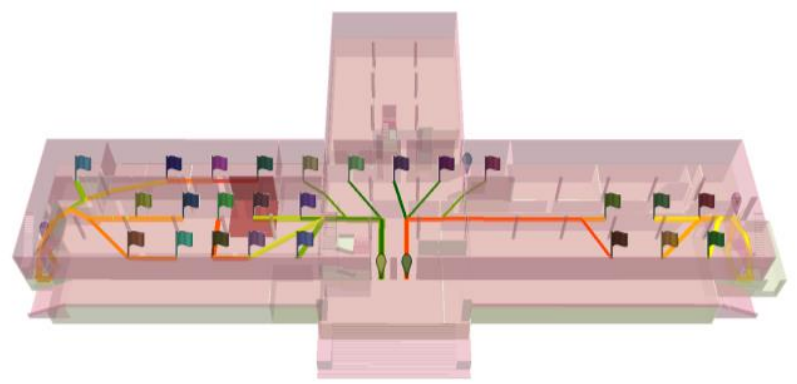

Figure 31. Generated Evacuation Ground Floor Routes of Library Patrons for Third Evacuation Scenario

The routes in the north wing of the ground floor showed small differences in the evacuation route as each origin point mainly evaded the source of fire.

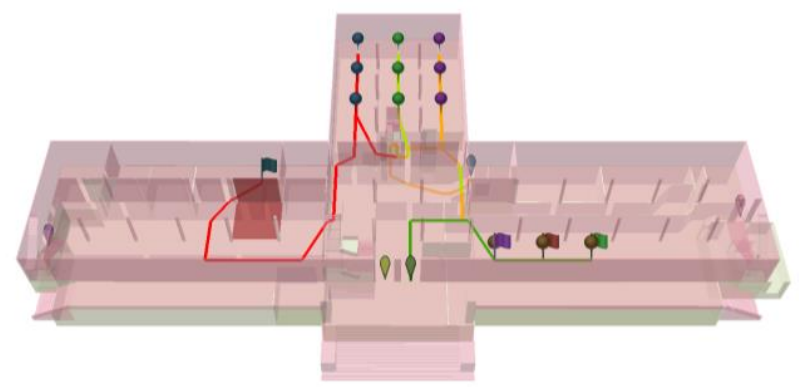

Figure 32. Generated Evacuation Ground Floor Routes of Library Staff for Third Evacuation Scenario

For the third scenario, it was mostly the staff from Electronic Resources in the ground floor who were affected. The shortest route of going from the electronic resources room to the storage room had to be ignored and the next possible path was used. In this scenario, no particular exit points experienced congestion as only one or two routes from either patrons or staff were rerouted. This change in path resulted to an excess in evacuation time of 2.36 seconds.

\subsection{New Exit Points}

The number and location of street level exit points were also assessed. Possible locations of new exit points were identified based on their plausibility to be realized and their impact on the evacuation process. The location-allocation layer was employed to determine which of the possible exit points yielded the best routes.

Since the east wing of the Main Library is utilized for storage purposes, creating new fire exits for this side of the building was deemed necessary in order to ease the flow of evacuation of staff with special assignments. The current evacuation plan only has the east basement exit as the main exit point of these staff members and those coming from the upper floors still had to use the service stairs in the wing during the evacuation process since they have no direct access to street level exit points.

Instead of using the service stairs in the storage room, staff from the second and ground floors can now directly head to the doors leading to the emergency staircase in the south side. Staff in the basement can now also head directly to the exit door in the south side of the east wing to reach safety. With this new exit point, there will be less congestion in the east basement exit and in the service stairs in the storage rooms. 


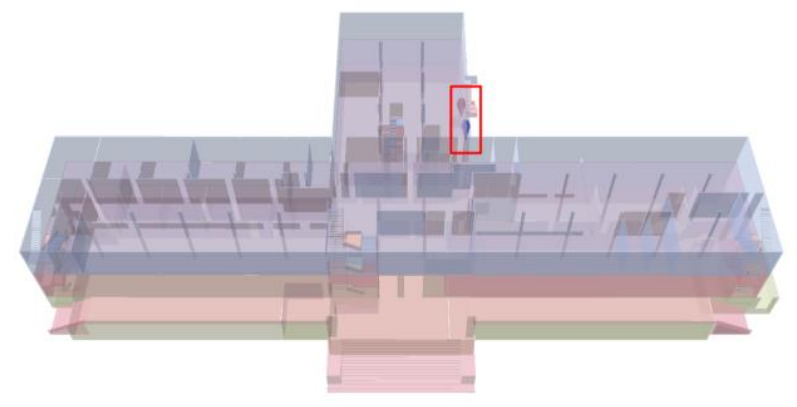

Figure 33. New East Wing Exits

Using the east basement exit resulted to a total evacuation time of 130.59 seconds but with the proposed new exits, the total evacuation time for the Main Library could only be 125.67 seconds. The average evacuation time also decreased to 96.84 seconds from 112.31 seconds. The 15.25 -second difference between the two could ease the evacuation process for staff members assigned to save the resources of the Main Library.

\section{CONCLUSIONS AND RECOMMENDATIONS}

\subsection{Conclusions}

In this study, evacuation routes for both patrons and library staff were generated with shortest distance and time to reach an exit point as the parameters for the creation of the routes. These generated evacuation routes were then compared to the current evacuation plans of the Main Library to assess the effectiveness of the current routes. Since the generated evacuation routes of the study were mostly similar to those of the current evacuation routes, it can be concluded that the current evacuation plan is sufficient to meet the needs of the building should a fire incident occur. Only a few generated routes deviated from the current evacuation plans of the Main Library, which were all located in the basement. These routes can be analyzed further to ensure the best possible evacuation paths for these locations.

Since the indoor network of the pathways inside the structure are in 3D, it is imperative that models that represent them and the evacuation in them be done in 3D. This added dimension improves the potential of the scenarios to be visualized and understood better by building occupants.

New evacuation routes were also created to save the many resources of the Main Library. Some staff members were designated to save these resources in case of fire incidents. The routes created for these staff members included the location of priority resources, where they were to head first, before proceeding to an exit point. Since these routes involved at least three 15 -second stops for the staff to save resources in various locations, these generated routes understandably have longer evacuation times.

The travel time of each evacuation route obtained from network analysis considered a constant speed of $1.788 \mathrm{~m} / \mathrm{s}$. The time of total evacuation - which is the time the last individual in the building reaches an exit or safety point - can be determined using the generated travel time of evacuation routes. From the results, the total time of evacuation of the Main Library is 130.59 seconds or approximately 2 minutes and 11 seconds, which is from a library staff evacuation route.

The fire obstruction scenarios created provided a test of flexibility for the generated evacuation routes. These scenarios were constructed based on the possible locations of where fire accidents could initially begin. Possible blockages were considered, and new evacuation routes were generated to avoid direct contact with fire. With these new routes, congestion in certain passages and exit points can be seen. These points of conflict can be assessed and evaluated in the future to accommodate such occurrences.

While the current number of street level exit points of the Main Library is sufficient for patrons and regular library staff members, the addition of a fire exit staircase in the south side of the east wing can help ease the flow of evacuation of staff assigned to save valuable resources. The total distance these staff members have to travel to reach a point of safety is shorter, and total time it takes to get to that point is also lesser. This will allow for lesser casualties in case of fire incidents for these staff members since the average evacuation time could be reduced by 15.25 seconds.

\subsection{Recommendations}

Since the evacuation routes produced from this study included the time of evacuation, these route times can be used for assessment when implementing evacuation procedures in the building. The results showed that the total evacuation time of the building is 2 minutes and 11 seconds should the speed of evacuees be $1.788 \mathrm{~m} / \mathrm{s}$.

During fire evacuation drills, this time can be used as the target time for everyone to vacate the building, or at least as a base time for the evacuation process. Since human behavior during an evacuation was not considered in the study and the speed used was constant, real life drills could yield different results since these two factors have a significant effect on the evacuation process.

Further studies on congestion in exit points, corridors, and stairways can also be performed from this research. While the results showed the exit points that had the highest count, these numbers do not fully reflect the possible congestion problems that could occur during emergency evacuations.

This indoor routing project can also be made available to firemen in case of fire emergencies. Firemen unfamiliar with the indoor layout of the building can use the network created to study the possible routes that can be traversed inside. The capability of network analysis to create points of blockages and generate new routes can also provide assistance during rescue missions.

Real life fire incidents always lead to deviations in the evacuation routes suggested in the emergency management plans. These obstruction scenarios can be used as a guide to further assess the efficiency of the evacuation process in the Main Library. Moreover, congestion problems in exit points can be studied, as well as the need for more street level exit points. Library patrons and staff can also use the generated routes to reach the next closest exit point should the closest one be made unavailable.

\section{ACKNOWLEDGEMENTS}

The researchers would like to thank both Mr. Edwin Gerodias and Mr. Rhoel Rondilla from the University Library, UPDiliman for making time to be interviewed and even provided some moral support with our research. 


\section{REFERENCES}

Cao, Y., Lu, F., 2012. Three-Dimensional Modeling for Buildings Evacuation Management. University of Gävle.

Kwan, M.P., Lee, J., 2005. Emergency Response after 9/11: The Potential of Real-Time 3D GIS for Quick Emergency Response in Micro-Spatial Environments. Comput. Environ. Urban Syst. 29 , 93-113.

https://doi.org/10.1016/j.compenvurbsys.2003.08.002

Main Library | University Library, University of the Philippines Diliman [WWW Document], n.d.

Makdoom, U., 2015. 3D Indoor Routing and Visualization for the University of Redlands. University of Redlands.

Musliman, I.A., Rahman, A.A., Coors, V., 2008. Implementing 3D Network Analysis in 3D-GIS. Int. Arch. Photogramm. Remote Sens. Spat. Inf. Sci. 37, 913-918.

Tang, F., Ren, A., 2011. GIS-based 3D evacuation simulation for indoor fi re. Build. Environ. 49, 193-202. https://doi.org/10.1016/j.buildenv.2011.09.021

Tsiliakou, E., Dimopoulou, E., Vi, C., Vi, W.G., 2016. 3D Network Analysis For Indoor Space Applications. Int. Arch. Photogramm. Remote Sens. Spat. Inf. Sci. XLII, 147-154. https://doi.org/10.5194/isprs-archives-XLII-2-W2-147-2016

University Library | University Library, University of the Philippines Diliman [WWW Document], n.d.

Xiong, Q., Zhu, Q., Du, Z., Zhu, X., Zhang, Y., Niu, L., Li, Y., 2017. A Dynamic Indoor Field Model for Emergency Evacuation Simulation. Int. J. Geo-Information 1-28. https://doi.org/10.3390/ijgi6040104 